\title{
Mesenchymal stromal cells suppress synovial fluid-derived $t$ cells from juvenile idiopathic arthritis patients in vitro
}

\author{
J Wienke* ${ }^{*}$ S de Roock, J Swart, A Martens, N Wulffraat, B Prakken \\ From 21st European Pediatric Rheumatology (PReS) Congress \\ Belgrade, Serbia. 17-21 September 2014
}

\begin{abstract}
Introduction
Mesenchymal stromal cells (MSC) are multipotent cells with an immunosuppressive capacity. In the last decade the feasibility and safety of MSC therapy has been established in various inflammatory diseases, including graft versus host disease. MSC are known to suppress $\mathrm{T}$ cell function and modulate $\mathrm{T}$ helper 17 (Th17) cells and regulatory $\mathrm{T}$ cells (Tregs), which play an important role in the pathogenesis of juvenile idiopathic arthritis (JIA). MSC may therefore serve as a new treatment option for JIA patients refractory to conventional therapies. However, it is unknown whether MSC are capable of suppressing the highly inflammatory synovial fluid mononuclear cells (SFMC), which have been shown to be resistant to suppression by Tregs. Furthermore, the effect of the inflammatory environment on MSC function is largely unknown, though it has been suggested that proinflammatory cytokines can enhance the suppressive potential of MSC.
\end{abstract}

\section{Objectives}

We aimed to study the in vitro immunomodulatory effects of MSC on SFMC from JIA patients, with a focus on $\mathrm{T}$ cell function. In addition, we assessed the influence of the inflammatory micro-environment, i.e. monocytes and proinflammatory cytokines, on the suppressive potential of MSC.

\section{Methods}

MSC were cocultured with either peripheral blood mononuclear cells (PBMC) or synovial fluid mononuclear cells (SFMC) from JIA patients (paired samples) or PBMC from healthy controls. We analyzed the effect of
MSC on T cell proliferation and Th17 and Treg numbers by flow cytometry. Cytokine production was analyzed in the culture supernatant by Luminex assay. Furthermore, we depleted monocytes from culture and blocked the proinflammatory cytokines TNF $\alpha$, IFN $\gamma$, IL-1 $\beta$ and IL- 6 to assess the result on MSC-mediated suppression.

\section{Results}

MSC suppressed proliferation of PB T cells and SF T cells from JIA patients dose-dependently, but patient-derived $\mathrm{T}$ cells were less susceptible to suppression than healthy donor-derived T cells. MSC reduced Th17 numbers and increased Treg numbers in PBMC, but not in SFMC. Addition of MSC did not clearly affect IL-17 levels in the supernatant, but TNF $\alpha$ production was suppressed in both PBMC and SFMC. Contrary to previous reports, blockade of TNF $\alpha$, IFN $\gamma$, IL- $1 \beta$ and IL- 6 during in vitro culture did not reduce suppression, but rather enhanced suppression in PBMC from JIA patients. Similarly, depletion of monocytes increased MSC-dependent suppression of healthy control PB T cells.

\section{Conclusion}

MSC suppress proliferation of synovial fluid T cells from JIA patients in a dose-dependent manner. However, patient-derived $\mathrm{T}$ cells are less susceptible to immunomodulation than healthy donor $\mathrm{T}$ cells. We propose that reduction of proinflammatory stimuli in conjunction with MSC therapy may benefit the suppressive effects of MSC in JIA.

\section{Disclosure of interest}

None declared. 
- Convenient online submission

- Thorough peer review

- No space constraints or color figure charges

- Immediate publication on acceptance

- Inclusion in PubMed, CAS, Scopus and Google Scholar

- Research which is freely available for redistribution 